\title{
APPLICATION OF RELIABILITY DESIGN METHODS TO DONGHAE HARBOR BREAKWATER
}

\author{
SEUNG-WOO KIM \\ Kunhwa Engineering Co., Ltd., 788-26 Yeoksam-Dong, Gangnam-Gu, Seoul 135-080, Korea; formerly, \\ Graduate Student, Department of Civil, Urban, and Geosystem Engineering, Seoul National University, E- \\ mail: seungwoo@kunhwaeng.co.kr \\ KYUNG-DUCK SUH ${ }^{*}$ \\ Department of Civil, Urban, and Geosystem Engineering \& Engineering Research Institute, Seoul \\ National University, San 56-1, Shinlim-Dong, Gwanak-Gu, Seoul 151-742, Korea, E-mail: \\ kdsuh@snu.ac.kr
}

${ }^{*}$ Corresponding author. Phone: +82-2-880-8760, Fax: +82-2-887-0349, E-mail: kdsuh@ snu.ac.kr 


\begin{abstract}
Reliability design methods have been developed for breakwater designs since the mid1980s. The reliability design method is classified into three categories depending on the level of probabilistic concepts being employed, i.e., Level 1, 2, and 3 methods. Each method gives results in different forms, but all of them can be expressed in terms of probability of failure so that the difference can be compared among the different methods. In this study, we apply the reliability design methods to the stability of armor blocks and sliding of caissons of the breakwater of Donghae Harbor located in the east coast of Korea, which was constructed by traditional deterministic design methods to be damaged in 1987 and reinforced in 1991. Analyses are made for the breakwaters before the damage and after the reinforcement. The allowable probability of failure of a Tetrapod armor layer of 50 year's lifetime is proposed as $40 \%$ for existing stability formulas, whilst that for caisson sliding as $20 \%$ with the failure criterion for the cumulative sliding distance over the lifetime of $0.1 \mathrm{~m}$. The probability of failure before the damage is much higher than the allowable value for both stability of armor blocks and sliding of caissons, indicating that the breakwater was under-designed. The probability of failure for the reinforced breakwater is lower than the allowable value, indicating that the breakwater became stable after the reinforcement. On the other hand, the results of different reliability design methods were in fairly good agreement, confirming that there is not much difference among the different methods.
\end{abstract}

Keywords: Breakwaters; armor blocks; caissons; reliability design methods; probability of failure. 


\section{Introduction}

The deterministic design method in civil engineering is to set a return period of loading events, to calculate the design loads corresponding to the return period, and to design a structure with a certain margin of safety. Uncertainties in the magnitudes of loading on and resistance of the structure are supposed to be covered by the safety margin. Therefore, it is difficult to consider the uncertainties of each design parameter separately and to evaluate the relative importance of different failure modes, so that there is always a possibility to over- or under-design the structure.

To overcome these shortcomings of the deterministic design, a probabilistic method has been proposed since the 1970s, which is called the reliability design method. For breakwaters, the reliability design methods have been developed since the mid-1980s, especially in Europe and Japan. In Europe, van der Meer (1988a) proposed a probabilistic approach for the design of breakwater armor layers, and Burcharth (1991) introduced the partial safety factors in the reliability design of rubble mound breakwaters. Recently Burcharth and Sørensen (2000) established partial safety factor systems for rubble mound breakwaters and vertical breakwaters by summarizing the results of the PIANC (Permanent International Association of Navigation Congresses) Working Groups. The European reliability design methods belong to what is called as Level 1 or 2 methods. On the other hand, in Japan, Level 3 methods have been developed, in which the expected sliding distance of a caisson of a vertical breakwater (Shimosako and Takahashi 2000; Goda and Takagi 2000) or the expected damage of armor blocks of a horizontally composite breakwater (Hanzawa et al. 1996) during their lifetime is estimated. Note that, in this paper, a composite breakwater covered with wave-energydissipating concrete blocks is termed a horizontal composite breakwater by following Takahashi (1997). Recently Suh et al. (2002) and Hong et al. (2004) respectively extended the methods of Hanzawa et al. (1996) and Shimosako and Takahashi (2000), to include the effect of the variability in wave direction.

Each reliability design method described above gives results in different forms, but all of them can be expressed in terms of probability of failure so that the difference can be compared among the different methods. Balas and Ergin (2002) have compared Level 2 and 3 methods for damage of armor units of a rubble mound breakwater by expressing the results as functions of exceedance probabilities of no damage with respect to time. In 
the present study, we apply the various reliability design methods to the stability of armor blocks and the sliding of caissons of the breakwater of Donghae Harbor located in the east coast of Korea, which was constructed by the traditional deterministic design method to be damaged in 1987 and reinforced in 1991. Analyses are made for the breakwaters before the damage and after the reinforcement so that the properness of the designs is investigated. Also comparison is made among different reliability design methods by expressing the results as functions of weight of armor blocks or width of a caisson with respect to probability of failure.

In the following section, a brief summary of the Donghae Harbor breakwater and the design waves is given. In Sec. 3, the reliability analyses for the stability of armor blocks are described. In Sec. 4, the reliability analyses for the sliding of caissons are described. The major conclusions then follow.

\section{Summary of Donghae Harbor Breakwater and Design Waves}

\subsection{Summary of the breakwater}

The Donghae Harbor was open on February 8, 1979, after about four years' construction work since 1975 with the deepwater design conditions of wave height of $8.4 \mathrm{~m}$, wave period of $14 \mathrm{~s}$, and principal wave directions of $\mathrm{NE}$ and $\mathrm{E}$, and the first phase development was completed in December 1983. The layout of Donghae Harbor is shown in Figure 1. Sections 8 to 11 of the North Breakwater indicated in the figure were constructed as a vertical breakwater, whilst Section 7 was constructed as a horizontally composite breakwater, which consists of a caisson covered with 25 ton Tetrapods, considering the connection with the seawall to the north. Thereafter, a length of $900 \mathrm{~m}$ (Sections 9 to 11 in Figure 1) was damaged by 10 to $15 \mathrm{~cm}$ sliding and tilting of caissons due to a winter storm in February 1987. The maximum significant wave height during the storm was measured to be $8.85 \mathrm{~m}$ in the offshore area. In 1991, a question was raised about the stability of the caisson of Section 11. The safety factor against sliding was calculated to be 1.06 , so Sections 8 to 11 were reinforced by placing stones of $0.015-0.03$

$\mathrm{m}^{3} /$ EA armored by two layers of 40 ton Tetrapods in front of the caisson. Section 7 was also reinforced by placing two layers of 40 ton Tetrapods on 25 ton Tetrapods. In this 
study, reliability analyses are made for the breakwaters of Sections 7 and 11. The crosssection of Section 7 after the reinforcement is shown in Figure 2, whilst the crosssections of Section 11 before and after the reinforcement are shown in Figures 3 and 4, respectively.

\subsection{Deepwater design waves}

In the redesign in 1991, deepwater wave direction of ENE, significant wave height of 7.6 $\mathrm{m}$, and wave period of $12 \mathrm{~s}$ were used for 50 year return period, which were estimated based on the report of Korea Fishery Agency (1988). However, this report does not provide the wave data of deepwater wave direction of ENE. Since detailed information about deepwater waves is necessary for reliability analyses, in this study, we use the data of deepwater wave direction of $\mathrm{NE}$ of the report, which give significant wave height of $8.2 \mathrm{~m}$ and wave period of $13 \mathrm{~s}$ for 50 year return period. These values were hindcasted by using the HYPA (HYbrid PArametrical) model and 44 major storms for 29 years (from 1959 till 1987). The wave heights and periods for other return periods are given in Table 1. The linear regression analysis of these values gives the relationship between deepwater significant wave height, $H_{0}$, and significant wave period, $T_{s}$, as

$$
T_{s}=1.454 H_{0}+0.824
$$

The cumulative probability distribution of the extreme wave height is given by the Weibull distribution:

$$
F(x)=1-\exp \left\{-\left[\frac{x-3.037}{1.493}\right]^{1.1}\right\}
$$

where $x$ stands for the annual maximum significant wave height.

\subsection{Design waves at the location of breakwater}

In the redesign in 1991, wave transformation from deep water to the location of the 
breakwater was calculated using the KORDI 88 model for the waves of deepwater direction of ENE to give significant wave height of $7.3 \mathrm{~m}$ and wave period of $12 \mathrm{~s}$ at the location of Section 11. In the present study, Kweon et al.'s (1997) wave transformation model was used with the aforementioned deepwater waves of direction of NE. Figure 5 shows the bathymetry of the numerical model domain. The significant wave heights at Sections 7 and 11 were calculated to be 5.73 and $7.64 \mathrm{~m}$, respectively. Although the deepwater wave conditions and wave transformation models are different between the redesign and the present study, the wave heights calculated at Section 11 do not show a big difference, partly proving that the wave conditions and the wave transformation model used in this study are reasonable. The significant wave heights and periods for different return periods at each section are presented in Table 2. The linear regression analyses of these values give the relationships between wave height and return period and between wave height and wave period, respectively, as

$$
\begin{array}{ll}
H_{s}=0.471 \ln T_{R}+3.872 ; & T_{s}=3.631 H_{s}-8.015 \quad(\text { Section } 7) \\
H_{s}=1.168 \ln T_{R}+3.067 ; & T_{s}=1.467 H_{s}+1.537 \quad(\text { Section } 11)
\end{array}
$$

where $H_{s}$ is the significant wave height at the location of the breakwater, and $T_{R}$ is the return period in years. Assuming that the extreme wave heights at the location of the breakwater are also described by the Weibull distribution, the parameters calculated using the values of wave heights and return periods are given in Table 2 , where $A, B$, and $k$ are the scale, location, and shape parameters, respectively, of the Weibull distribution.

\section{Reliability Analysis for Stability of Armor Blocks}

\subsection{Level 1 method for stability of armor blocks}

The Level 1 reliability analysis is performed using the partial safety factor system developed by Burcharth and Sørensen (2000). Since Section 7 is a horizontally composite breakwater armored with Tetrapods, it may be desirable to use the stability 
formula proposed by Hanzawa et al. (1996). For this formula, however, the coefficients required for the calculation of the partial safety factors are not presented. Therefore, we use the Hudson (1959) formula with the stability coefficient of 7.0, which is recommended by Shore Protection Manual (1984) for breaking waves acting on the trunk of a breakwater armored by Tetrapods. The stability number and the design equation for the Hudson formula are given by

$$
\begin{aligned}
& N_{s}=\frac{H_{s}}{\Delta D_{n}}=\left(K_{D} \cot \alpha\right)^{1 / 3} \\
& D_{n} \geq \frac{\gamma_{Z} \gamma_{H_{s}} H_{s}}{\left(K_{D} \cot \alpha\right)^{1 / 3} \Delta}
\end{aligned}
$$

respectively, where $N_{s}$ is the stability number, $\Delta$ the relative density of the armor block in water ( $=\rho_{s} / \rho-1 ; \rho_{s}=$ density of the block, $\rho=$ density of water), $D_{n}$ the nominal diameter of the block $\left(=V^{1 / 3} ; V=\right.$ volume of the block), $K_{D}$ the stability coefficient, $\alpha$ the angle of the front slope of the breakwater from horizontal plane, and $\gamma_{Z}$ and $\gamma_{H_{s}}$ are the partial safety factors for resistance and loading, respectively. $\rho_{s}=2300 \mathrm{~kg} / \mathrm{m}^{3}$ was used in this study.

Although Section 11 after reinforcement is backed by a caisson, the front part is a typical sloping breakwater. Therefore, the formula of van der Meer (1988c) is used, which gives the stability number and the design equation for Tetrapods as

$$
\begin{aligned}
& N_{s}=\frac{H_{s}}{\Delta D_{n}}=\left(3.75 \frac{N_{0}^{0.5}}{N^{0.25}}+0.85\right) s_{Z}^{-0.2} \\
& D_{n} \geq \frac{\gamma_{Z} \gamma_{H_{s}} H_{s}}{\left(3.75 \frac{N_{0}^{0.5}}{N^{0.25}}+0.85\right) s_{Z}^{-0.2}}
\end{aligned}
$$


respectively, where $s_{Z}$ is the wave steepness $\left(=2 \pi H_{s} /\left(g T_{Z}^{2}\right) ; g=\right.$ gravitational acceleration, $T_{Z}=$ mean wave period $\left.=T_{s} / 1.15\right), N_{0}$ the relative damage defined by van der Meer (1988c) as the number of displaced blocks within the width (along the breakwater alignment) of one nominal diameter $D_{n}$, and $N$ is the number of waves during a storm. In the present study, $N_{0}=1.5$ was used, which was proposed by van der Meer (1988c) for failure of Tetrapod armor layers. The number of waves was set to 1000, which corresponds to about three hours of storm duration. The significant wave periods are calculated by Eqs. (3) and (4) for given significant wave heights.

The partial safety factors, $\gamma_{H_{s}}$ and $\gamma_{Z}$, in Eqs. (6) and (8) are calculated by

$$
\begin{aligned}
& \gamma_{H_{s}}=\frac{H_{s}^{T_{P_{f}}}}{H_{s}^{T_{l^{\prime}}}}+\sigma_{F_{H_{s}}^{\prime}}^{\prime}\left(1+\left(\frac{H_{s}^{3 T_{l}}}{H_{s}^{T_{i}}}-1\right) k_{\beta} P_{f}\right)+\frac{k_{s}}{\sqrt{P_{f} N_{e}}} \\
& \gamma_{Z}=1-k_{\alpha} \ln P_{f}
\end{aligned}
$$

respectively, where $T_{l}$ is the lifetime of the breakwater, $P_{f}$ the probability of failure during the lifetime, $H_{s}^{T_{l}}$ and $H_{s}^{3 T_{l}}$ the significant wave heights of the return period of $T_{l}$ and $3 T_{l}$ years, respectively, and $H_{s}^{T_{P_{f}}}$ is the significant wave height corresponding to the equivalent return period $T_{P_{f}}$, which is calculated from the encounter probability formula $T_{P_{f}}=\left(1-\left(1-P_{f}\right)^{1 / T_{l}}\right)^{-1} . \sigma_{F_{H_{s}}}^{\prime}$ is the variational coefficient of a function $F_{H_{s}}$ modeled as a factor on $H_{s} . F_{H_{s}}$ signifies the measurement errors and short term variability of $H_{s}$ and has the mean value 1.0. $N_{e}$ is the number of data used for fitting 
the extreme distribution, which is 44 in this study. $k_{\alpha}, k_{\beta}$, and $k_{s}$ are the coefficients which are determined in the optimization procedure of the partial safety factors. $k_{\alpha}=0.036$ and $k_{\beta}=151$ are used for the Hudson formula, and $k_{\alpha}=0.026$ and $k_{\beta}=38$ for the van der Meer formula. The coefficient $k_{s}$ is constant as 0.05 . The coefficients for the Hudson formula were proposed for rocks, but they are used for Tetrapods in this study. $\sigma_{F_{H_{s}}}^{\prime}=0.15$ was used as suggested by Burcharth and Sørensen (2000), because the offshore wave height was determined by hindcasting and the wave height at the breakwater was calculated by a numerical model. The lifetime of the breakwater was assumed to be the same as the return period of the design wave, i.e. 50 years. $H_{s}^{T_{l}}, H_{s}^{3 T_{l}}$, and $H_{s}^{T_{P_{f}}}$ are calculated by Eqs. (3) and (4) for the given return period.

Figure 6 shows the relation between the probability of failure and the weight of Tetrapods for each section for the return period of 50 years. The probability of failure for 25 ton Tetrapods of Section 7 before reinforcement is about $60 \%$, whilst it is about $18 \%$ for 40 ton Tetrapods after reinforcement. It is also about $18 \%$ for 40 ton Tetrapods of Section 11 after reinforcement. It is shown that for a certain weight of Tetrapods the probability of failure in shallow water depths is larger than that in deeper waters for smaller weights and vice versa for larger weights.

\subsection{Level 2 method for stability of armor blocks}

The Level 2 method also uses the Hudson formula for Section 7 and the van der Meer formula for Section 11. In Tables 3 and 4 are given the mean, standard deviation, coefficient of variation, and probability distribution of each design variable for the Hudson and van der Meer formulas, respectively, which were obtained based on van der Meer (1988a) and the PIANC (1992) report.

The reliability functions of the Hudson and van der Meer formulas for Tetrapods are given by 


$$
\begin{aligned}
& f=a_{1} \Delta D_{n}\left(K_{D} \cot \alpha\right)^{1 / 3}-\left(H_{s}+F_{H_{s}}\right) \\
& f=a_{2} \Delta D_{n}\left(3.75 \frac{N_{0}^{0.5}}{N^{0.25}}+0.85\right)-\left(H_{s}+F_{H_{s}}\right) s_{Z}^{0.2}
\end{aligned}
$$

respectively, where $a_{1}$ and $a_{2}$ are variables signifying the uncertainty inherent in each formula. The design variables were assumed to be independent one another because there is no data for the correlations among them. The first-order reliability method (FORM) with approximate full distribution approach (AFDA) was used, which calculates the design points of each variable and the reliability index by iteration (Ang and Tang 1984). Only several times of iteration were needed for the tolerance of the difference of the reliability indices of 0.001 .

The results of the Level 2 analysis are shown in Figure 7. The probability of failure for 25 ton Tetrapods of Section 7 before reinforcement is about $60 \%$ as in the Level 1 method, whilst it is about $23 \%$ for 40 ton Tetrapods after reinforcement, somewhat larger than the result of Level 1 method. It is also about $25 \%$ for 40 ton Tetrapods of Section 11 after reinforcement. As in the Level 1 analysis, for a certain weight of Tetrapods the probability of failure in shallow water depths is larger than that in deeper waters for smaller weights and vice versa for larger weights.

\subsection{Level 3 method for stability of armor blocks}

In the Level 3 method, the van der Meer formula is used for Section 11 as in the Level 1 and 2 methods, but the Hanzawa et al.'s (1996) formula is used for Section 7, which was proposed for a horizontally composite breakwater and is given by

$$
N_{s}=\frac{H_{s}}{\Delta D_{n}}=2.32\left(\frac{N_{0}}{N^{0.5}}\right)^{0.2}+1.33
$$


Because the Hudson formula was used for Section 7 in the Level 1 and 2 methods, the value of $N_{0}$ corresponding to the Hudson formula should be determined. Figure 8 compares the weight of Tetrapods using the Hanzawa et al.'s formula having various values of $N_{0}$ with that using the Hudson formula. As shown in the figure, the Hanzawa et al.'s formula using $N_{0}=0.2$ coincides with the design using the Hudson formula. Therefore, $N_{0}=0.2$ was used for failure of Tetrapods in this study. On the other hand, $N_{0}=1.5$ was used for the van der Meer formula as he suggested.

The Level 3 analysis for the stability of armor units was performed following the procedure of Hanzawa et al. (1996) and Suh et al. (2002). The number of simulations to calculate the probability of failure was 2000 . The probability of failure is calculated as the percentage of the simulations of the cumulative damage exceeding the allowable value (0.2 and 1.5 for Hanzawa et al. and van der Meer formula, respectively) out of 2000 simulations. The offshore wave height was determined using the Weibull distribution given by Eq. (2), and the corresponding wave period was calculated by Eq. (1). The Kweon et al.'s (1997) model was used with the model domain shown in Figure 5 to calculate the waves at the location of the breakwater. The peak value of directional spreading parameter, $s_{\max }=20$, the principal wave direction, $\left(\alpha_{p}\right)_{0 D}=22.5^{\circ}$, and its standard deviation, $\sigma_{\left(\alpha_{p}\right)_{0}}=15.8^{\circ}$, in deep water, were used. The water level was calculated using the tidal range of $0.392 \mathrm{~m}$ and the probability density function of tidal elevation proposed by Cho et al. (2004):

$$
p_{T}(\eta)=\frac{A}{2}\left\{\frac{1}{\sigma_{1} \sqrt{2 \pi}} \exp \left[-\frac{1}{2}\left(\frac{\eta-\mu_{1}}{\sigma_{1}}\right)^{2}\right]+\frac{1}{\sigma_{2} \sqrt{2 \pi}} \exp \left[-\frac{1}{2}\left(\frac{\eta-\mu_{2}}{\sigma_{2}}\right)^{2}\right]\right\}
$$

where $\eta$ is the tidal elevation, $A$ the scale parameter satisfying $\int_{-\infty}^{\infty} p_{T}(\eta) d \eta=1.0$, and $\mu_{1}, \mu_{2}$ and $\sigma_{1}, \sigma_{2}$ are means and standard deviations, respectively. The means and standard deviations at Donghae Harbor are $\mu_{1}=-7.21 \mathrm{~cm}, \mu_{2}=7.02 \mathrm{~cm}$, $\sigma_{1}=10.67 \mathrm{~cm}$, and $\sigma_{2}=11.33 \mathrm{~cm}$. The bias and deviation coefficient were 0.0 and 0.1 , respectively, for wave heights and periods in both offshore area and the location of the 
breakwater.

The results of the Level 3 analysis are shown in Figure 9. The probabilities of failure for 25 ton Tetrapods before reinforcement and 40 ton Tetrapods after reinforcement of Section 7 are $40 \%$ and 3\%, respectively, both being much smaller than those calculated by Level 1 or 2 method. The probability of failure for 40 ton Tetrapods of Section 11 after reinforcement is about 20\%, which lies between the results of Level 1 and Level 2. The trend that the probability of failure in shallow water depths is larger than that in deeper waters for smaller weights of Tetrapods and vice versa for larger weights is shown more obviously than the results of Level 1 and 2.

Figure 10 shows the relation between the weight of Tetrapods and the relative damage. For Section 7 where the Hanzawa et al.'s formula was used with the relative damage of failure of 0.2 , the weight of Tetrapods corresponding to the damage of 0.2 is about 25 ton. On the other hand, for Section 11 where the van der Meer's formula was used with the damage of failure of 1.5 , the weight of Tetrapods corresponding to the damage of 1.5 is about 30 ton, which is not much different from the weight corresponding to $N_{0}=0.2$ in Section 7. Although a glance at Figure 10 makes one think that the results at the two sections look quite different, a big difference is not shown between the weights of Tetrapods calculated by the different formulas with different values of damage of failure. Figure 11 shows the relation between the relative damage and the probability of failure. Although the results of the two sections seem to be quite different as in Figure 10, the probability of failure for the relative damage of failure is about $40 \%$ for both sections.

\subsection{Evaluation of stability of armor blocks}

We try to evaluate the stability of armor blocks of the Donghae Harbor breakwater before and after the reinforcement based on the results of the above reliability analyses. For this, first the allowable probability of failure should be determined. Although allowable probabilities of failure have been proposed by Nagao et al. (1995) and Shimosako and Takahashi (1998) for the sliding of caissons of vertical breakwaters, none has been proposed for stability of armor blocks. The probabilities of failure calculated by various reliability methods for different sections in this study are summarized in Table 5. Based on this table and Figure 11, we propose the allowable probability of failure for armor 
blocks of breakwaters of 50 year's lifetime as $40 \%$. For Section 7 before the reinforcement, the probability of failure was calculated to be larger than the allowable value $40 \%$ by all the reliability methods, indicating that the armor blocks were unstable. On the contrary, in both sections after the reinforcement the probability of failure was calculated to be smaller than $40 \%$, indicating that the armor blocks after the reinforcement are stable.

\subsection{Comparison of reliability design methods for stability of armor blocks}

In this section, the difference among the reliability methods is examined by comparing the results of different methods used in different sections. Figure 12 shows the relation between the probability of failure and the weight of Tetrapods calculated by each method for Section 7. The Level 1 and 2 methods give similar results, whilst the Level 3 method gives a smaller weight than other methods for smaller probabilities of failure. One of the reasons why the Level 3 method gives relatively large difference from other methods may be to use a different formula for armor stability; for Section 7, the Hudson formula was used in Level 1 and 2 methods, whilst the Hanzawa et al.'s formula in Level 3 method. Although the latter formula was used with a relative damage of failure that was determined for the two formulas to give similar weights of Tetrapods for the same wave height (see Figure 8), the fundamental difference between the formulas could not be overcome.

Figure 13 shows the relation between the probability of failure and the weight of Tetrapods calculated by each method for Section 11. In this section, the van der Meer formula was used for all the methods. On the whole, the different methods give similar results, though the Level 3 and Level 1 methods give somewhat smaller weights than other methods for smaller and larger probabilities of failure, respectively.

As seen in Figures 12 and 13, the Hanzawa et al.'s (1996) formula used for Section 7 in the Level 3 method shows a different behavior from other formulas, i.e., rapid increase of probability of failure with decreasing weight of Tetrapods. For example, for Section 7 , when the weight decreases from 25 ton to 20 ton, the probability of failure increases from $40 \%$ to $90 \%$ for the Hanzawa et al.'s formula, while it does from $60 \%$ to $80 \%$ for the Hudson formula in the Level 2 method. Cautions should be made in using the Hanzawa et al.'s formula because a small decrease of weight of Tetrapod can increase the 
probability of failure largely.

\section{Reliability Analysis for Sliding of Caisson}

The reliability analyses of caisson sliding are performed only for Section 11, since no damage has occurred in Section 7 during the 1987 storm.

\subsection{Level 1 method for sliding of caisson}

As with the stability of armor units, the Level 1 analysis for the sliding of a caisson of a vertical breakwater is performed using the partial safety factor system developed by Burcharth and Sørensen (2000). The design equation for the sliding of a caisson is given by

$$
f=\frac{\mu\left(W_{w}-0.77 U\right)}{\gamma_{Z}}-0.9 P \geq 0
$$

where $\mu$ is the friction factor between the caisson and the mound, $W_{w}$ the weight of the caisson installed in water, and $P$ and $U$ are the total horizontal and uplift pressures, respectively, calculated by the Goda (1974) formula incorporated with the impulsive pressure coefficients proposed by Takahashi et al. (1994). Note that the wave height is multiplied by the partial safety factor for loading, $\gamma_{H_{s}}$, in the calculation of the pressures. The values of 0.77 and 0.9 are the bias factors. For the caisson of Section 11 covered with stones and Tetrapods after the reinforcement, the wave pressures and the elevation of pressure exertion are reduced by $20 \%$ (Korea Port and Harbor Association 2000).

Each part of the caisson has different densities. It is difficult to consider the density difference in the calculation of the stability of a caisson with variable widths. In this study, we used a constant density, which is obtained by dividing the total weight of a caisson by the volume. The constant densities were 1955 and $2021 \mathrm{~kg} / \mathrm{m}^{3}$ for the caissons before the damage and after the reinforcement, respectively. 
Since the offshore wave height was determined by hindcasting and the wave height at the breakwater was calculated by a numerical model, the partial safety factors corresponding to $\sigma_{F_{H_{s}}}^{\prime}=0.2$ were used, which are given in Table 6 along with the corresponding probabilities of failure. For these values, the caisson widths satisfying $f=0$ in Eq. (15) were calculated.

Figure 14 shows the relation between the probability of failure and the width of caisson for the cross-sections before and after reinforcement for the return period of 50 years. The probability of failure for the caisson width of $20 \mathrm{~m}$ before reinforcement is greater than $40 \%$, whilst it is about $20 \%$ for the same caisson width after reinforcement.

\subsection{Level 2 method for sliding of caisson}

The reliability function for the sliding of a caisson of a vertical breakwater is given by

$$
f=\mu\left(W_{w}-U\right)-P
$$

The AFDA was used for the Level 2 analysis of the stability of armor blocks because the wave heights were assumed to follow a non-normal distribution, i.e., Weibull distribution. However, all the design variables in the preceding equation are assumed to follow a normal distribution, so the first-order design value approach (FDA) was used, which is simpler than the AFDA. The mean, standard deviation, coefficient of variation, and probability distribution of each design variable are given in Table 7, which were obtained based on Takayama and Ikeda (1992), Bruining (1994), van der Meer et al. (1994), Nagao et al. (1995, 1997, 1998), Kawai et al. (1997), and Shimosako and Takahashi $(1998,2000)$. The mean and standard deviation in the table were normalized with respect to the design value of each variable. The design value of $\mu$ was set to be 0.6. Again it is assumed that the design variables are independent one another.

Note that the statistical characteristics of $P$ and $U$ in Table 7 include the estimation errors of deepwater design wave, wave transformation and wave breaking in shallow sea as well as the Goda formula to calculate the wave forces. Takayama and Ikeda (1992) have proposed the mean and standard deviation of wave forces as 0.91 and 0.19 , respectively, by including only the estimation error of the Goda formula. 
The results of the Level 2 analysis are shown in Figure 15. The probability of failure for the caisson width of $20 \mathrm{~m}$ before reinforcement is about $95 \%$, whilst it is about $20 \%$ after the reinforcement as in the Level 1 method.

\subsection{Level 3 method for sliding of caisson}

The Level 3 analysis for the sliding of a caisson was performed following the procedure of Shimosako and Takahashi (2000) and Hong et al. (2004). The number of simulations to calculate the probability of failure was 5000. The probability of failure is calculated as the percentage of the simulations of the cumulative sliding distance over the lifetime exceeding an allowable value out of 5000 simulations. In this study, the allowable cumulative sliding distance of $0.1 \mathrm{~m}$ was used. The calculation of offshore waves and water levels and the corresponding waves at the location of the breakwater was the same as that explained in section 3.3. On the other hand, the bias and deviation coefficient for the wave periods of individual waves were 0.0 and 0.1 , respectively.

The results of the Level 3 analysis are shown in Figure 16. The probability of failure for the caisson width of $20 \mathrm{~m}$ before reinforcement is about $80 \%$, whilst it is about $16 \%$ after the reinforcement, which is close to those in the Level 1 and 2 methods.

Figure 17 shows the relation between the caisson width and the expected sliding distance for the breakwaters before and after the reinforcement. For the allowable expected sliding distance of $0.1 \mathrm{~m}$ proposed by Goda and Takagi (2000), the caisson width of $27.1 \mathrm{~m}$ is required for the breakwater before the reinforcement, whilst $19.1 \mathrm{~m}$ is required after the reinforcement.

Figure 18 shows the relation between the expected sliding distance and the probability of failure. For the expected sliding distance of $0.1 \mathrm{~m}$, the probability of failure is about $20 \%$ both before and after the reinforcement. One may think that the

probability of failure corresponding to the expected sliding distance of $0.1 \mathrm{~m}$ must be $50 \%$ because we use the cumulative sliding distance of $0.1 \mathrm{~m}$ as the criterion for failure. This is true if the distribution of the cumulative sliding distance has a small skewness. If the distribution is skewed to the right (or a longer tail occurs towards larger values), however, the percentage of the values larger than the mean is smaller than $50 \%$. The distribution of the cumulative sliding distance is severely skewed to the right as shown in Figure 19, which shows the number of occurrence of the cumulative sliding distance for 
the caisson of width of $19.1 \mathrm{~m}$ after the reinforcement. In the figure, the value in the range of 0 to $0.1 \mathrm{~m}$ includes the cases of zero sliding distance, and the number of occurrence of the cumulative sliding distance greater than $2 \mathrm{~m}$ is drawn in the range of 2.0 to $2.1 \mathrm{~m}$. The expected (or mean) sliding distance in this case is $0.1 \mathrm{~m}$, but the percentage of the values greater than $0.1 \mathrm{~m}$ is only $23 \%$. On the other hand, Goda and Takagi (2000) showed that the mean sliding distance of upper $10 \%$ is 7.5 times the expected sliding distance. The mean of upper $10 \%$ of the results in Figure 19 is $0.659 \mathrm{~m}$, which is 6.6 times the expected sliding distance, being close to the value proposed by Goda and Takagi.

\subsection{Evaluation of stability of caissons against sliding}

We evaluate the stability of caissons against sliding based on the results of the above reliability analyses. First the allowable probability of failure is determined using the results of the Level 3 method. As shown in Figure 18, the probability of failure is about $20 \%$ for the allowable expected sliding distance of $0.1 \mathrm{~m}$ proposed by Goda and Takagi (2000), which lies between the maximum and minimum values of allowable probability of failure proposed by Shimosako and Takahashi (1998). Therefore, we use the allowable probability of failure of $20 \%$ with the failure criterion for cumulative sliding distance of $0.1 \mathrm{~m}$.

The probabilities of failure calculated by various reliability design methods are summarized in Table 8. For the breakwater before reinforcement, the probability of failure was calculated to be much larger than the allowable value $20 \%$ by all the reliability methods, indicating that the caissons were unstable against sliding. On the contrary, for the breakwater after reinforcement, all the methods give the probability of failure of about $20 \%$, indicating that the caissons became stable after the reinforcement.

\subsection{Comparison of reliability design methods for stability of caissons against sliding}

In this section, the difference among the reliability methods is examined by comparing the results of different methods. Figures 20 and 21 respectively show the relation between the probability of failure and the caisson width calculated by each method before and after the reinforcement. The Level 2 and 3 methods give similar results on the 
whole, whilst the Level 1 method gives somewhat a larger caisson width than other methods for smaller probabilities of failure.

\section{Conclusions}

In this study, various reliability design methods have been applied to the breakwater of Donghae Harbor, which was constructed by the conventional deterministic design method to experience severe damage and subsequent reinforcement. Major conclusions of the present paper are as follows:

(1) In spite of different criteria of failure for relative damage of an armor layer for different formulas, the allowable probability of failure of the Tetrapod armor layer of a breakwater of 50 year's lifetime is estimated to be about $40 \%$. However, further study is required for the difference of allowable relative damages proposed for different formulas.

(2) When we use $0.1 \mathrm{~m}$ as the failure criterion for the cumulative sliding distance of a caisson over the lifetime, the allowable probability of failure for caisson sliding is about $20 \%$, which was found to correspond to the expected sliding distance of $0.1 \mathrm{~m}$ proposed by Goda and Takagi (2000).

(3) Based on the allowable probabilities of failure proposed above, the breakwater of Donghae Harbor is judged to be under-designed before the damage but become stable after the reinforcement.

(4) The results of the different reliability design methods are in fairly good agreement, showing that there is not much difference among the different methods.

\section{Acknowledgements}

This work was supported by the Project for Development of Next Generation Technical Standard of Harbor Structures of Korea Ministry of Marine Affairs and Fisheries and the Research Project for Development of Reliability Design Methods of Breakwaters of Daewoo Engineering \& Construction Company. 


\section{References}

Ang, A. H.-S. and Tang, W. H. [1984] Probability Concepts in Engineering Planning and Design (John Wiley \& Sons, Inc., New York).

Balas, C. E. and Ergin, A. [2002] "Reliability-based risk assessment in coastal projects: Case study in Turkey," J. Waterway, Port, Coastal and Ocean Engrg., American Soc. of Civil Engrs., 128(2), 52-61.

Bruining, H. F. [1994] "Wave forces on vertical breakwaters: Reliability of design formula," Delft Hydraulics Rep. H1903, MAST II.

Burcharth, H. F. [1991] "Introduction of partial coefficient in the design of rubble mound breakwaters," Proc. Conf. on Coastal Structures and Breakwaters, Inst. of Civil Engrs., London, pp. 543-565.

Burcharth, H. F. and Sørensen, J. D. [2000] "The PIANC safety factor system for breakwaters," Proc. Int. Conf. Coastal Structures '99, A. A. Balkema, Spain, pp. 1125-1144.

Cho, H. Y., Jeong, S. T. and Oh, Y. M. [2004] "Estimation of probability density function of tidal elevation data," J. Korean Soc. of Coastal and Ocean Engrs., 16(3), 152-161 (in Korean).

Goda, Y. [1974] "A new method of wave pressure calculation for the design of composite breakwater," Proc. 14th Int. Conf. on Coastal Engrg., American Soc. of Civil Engrs., Copenhagen, pp. 1702-1720.

Goda, Y. and Takagi, H. [2000] "A reliability design method of caisson breakwaters with optimal wave heights," Coastal Engrg. J., 42(4), 357-387.

Hanzawa, M., Sato, H., Takahashi, S., Shimosako, K., Takayama, T. and Tanimoto, K. [1996] "New stability formula for wave-dissipating concrete blocks covering horizontally composite breakwaters," Proc. 25th Int. Conf. on Coastal Engrg., American Soc. of Civil Engrs., Orlando, pp. 1665-1678.

Hong, S. Y., Suh, K. D. and Kweon, H.-M. [2004] "Calculation of expected sliding distance of breakwater caisson considering variability in wave direction," Coastal Engrg. J., 46(1), 119-140.

Hudson, R. Y. [1959] "Laboratory investigation of rubble-mound breakwaters," J. of Waterways and Harbors Div., American Soc. of Civil Engrs., 85(WW3), 93-121. 
Kawai, H., Takayama, T., Suzuki, Y. and Hiraishi, T. [1997] "Failure probability of breakwater caisson for tidal level variation," Rep. of Port and Harbour Res. Inst., 36(4), 4-41 (in Japanese).

KFA [1988] Korea Fishery Agency, "Report of estimation of deep water waves (East Sea and South Sea)" (in Korean).

KPHA [2000] Korea Port and Harbor Association, Design Standards for Harbors and Fishery Ports (in Korean).

Kweon, H.-M., Sato, K. and Goda, Y. [1997] "A 3-D random breaking model for directional spectral waves," Proc. 3rd Int. Symp. Ocean Wave Measurement and Analysis, American Soc. of Civil Engrs., Norfolk, pp. 416-430.

Nagao, T., Kadowaki, Y. and Terauchi, K. [1995] "Evaluation of safety of breakwaters by the reliability based design method (1st Report: Study on the safety against sliding)," Rep. of Port and Harbour Res. Inst., 34(1), 40-70 (in Japanese).

Nagao, T., Kadowaki, Y., Tsuchida, T. and Terauchi, K. [1997] "Evaluation of safety of breakwaters by the reliability based design method (2nd Report: Study on the safety against foundation failure)," Rep. of Port and Harbour Res. Inst., 36(1), 26-56 (in Japanese).

Nagao, T., Okubo, N., Kawasaki, S. and Hayashi, Y. [1998] "Evaluation of safety of breakwaters by the reliability based design method (3rd Report: Concluding the applicability of reliability based design method)," Rep. of Port and Harbour Res. Inst., 37(2), 132-176 (in Japanese).

PIANC [1992] Permanent International Association of Navigation Congresses, “Analysis of rubble mound breakwaters," Report of Working Group No. 12 of the Permanent Technical Committee II, 46.

Shimosako, K. and Takahashi, S. [1998] "Reliability design method of composite breakwater using expected sliding distance," Rep. of Port and Harbour Res. Inst., 37(3), 4-30 (in Japanese).

Shimosako, K. and Takahashi, S. [2000] "Application of deformation-based reliability design for coastal structures," Proc. Int. Conf. Coastal Structures '99, A. A. Balkema, Spain, pp. 363-371.

SPM [1984] Shore Protection Manual, 4th edn., Waterways Experiment Station, Corps od Engineers, Coastal Engineering Research Center, U.S. Government Printing Office, Wahsington, D.C. 
Suh, K. D., Kweon, H.-M. and Yoon, H. D. [2002] "Reliability design of breakwater armor blocks considering wave direction in computation of wave transformation," Coastal Engrg. J., 44(4), 321-341.

Takahashi, S. [1997] "Breakwater design," in Handbook of Port and Harbor Engineering: Geotechnical and Structural Aspects, ed. G.P. Tsinker (Chapman \& Hall, New York), pp. 951-1043.

Takahashi, S., Tanimoto, K. and Shimosako, K. [1994] "A proposal of impulsive pressure coefficient for the design of composite breakwaters," Proc. Int. Conf. HydroTechnical Engrg. for Port and Harbour Constuction, Yokosuka, pp. 489-504.

Takayama, T. and Ikeda, N. [1992] "Estimation of sliding failure probability of present breakwaters for probabilistic design," Rep. of Port and Harbour Res. Inst., 31(5), 3-32. van der Meer, J. W. [1988a] "Deterministic and probabilistic design of breakwater armor layers," J. Waterway, Port, Coastal and Ocean Engrg., American Soc. of Civil Engrs., 114(1), 66-80.

van der Meer, J. W. [1988b] "Rock slopes and gravel beaches under wave attack," Ph.D. thesis, Delft University of Technology.

van der Meer, J. W. [1988c] "Stability of Cubes, Tetrapods and Accropode," Proc. Int. Conf. Breakwaters '88, American Soc. of Civil Engrs., pp. 59-68.

van der Meer, J. W., d'Angremond, K. and Juhl, J. [1994] "Probabilistic calculations of wave forces on vertical structures," Proc. 24th Int. Conf. on Coastal Engrg., American Soc. of Civil Engrs., Kobe, pp. 1899-1910. 
Table 1. Deepwater significant wave heights and periods for different return periods.

\begin{tabular}{ccc}
\hline Return period $(\mathrm{yr})$ & Wave height $(\mathrm{m})$ & Wave period $(\mathrm{s})$ \\
\hline 10 & 6.3 & 10.0 \\
20 & 7.1 & 11.0 \\
30 & 7.6 & 12.0 \\
50 & 8.2 & 13.0 \\
70 & 8.6 & 13.0 \\
100 & 9.0 & 14.0 \\
\hline
\end{tabular}


Table 2. Significant wave heights and periods for various return periods at different sections.

\begin{tabular}{ccccccc}
\hline \multicolumn{7}{c}{ Section 7, Water depth $=8.0 \mathrm{~m}$} \\
\hline Return period (yr) & 10 & 20 & 30 & 50 & 70 & 100 \\
Wave height (m) & 4.93 & 5.30 & 5.50 & 5.73 & 5.87 & 6.02 \\
Wave period (s) & 10.0 & 11.0 & 12.0 & 13.0 & 13.0 & 14.0 \\
\hline Parameters of Weibull distribution: & $A=1.743$, & $B=2.280$, & $k=2.0$ \\
\hline \multicolumn{7}{c}{ Section 11, Water depth = 18.5 m } \\
\hline Return period (yr) & 10 & 20 & 30 & 50 & 70 & 100 \\
Wave height (m) & 5.75 & 6.58 & 7.05 & 7.64 & 8.03 & 8.44 \\
Wave period (s) & 10.0 & 11.0 & 12.0 & 13.0 & 13.0 & 14.0 \\
\hline Parameters of Weibull distribution: $A=1.437$, & $B=2.678, k=1.1$ \\
\hline
\end{tabular}


Table 3. Statistical characteristics of design variables for Hudson (1959) formula.

\begin{tabular}{ccccc}
\hline Variable & Mean & $\begin{array}{c}\text { Standard } \\
\text { deviation }\end{array}$ & $\begin{array}{c}\text { Coefficient of } \\
\text { variation }\end{array}$ & Distribution \\
\hline$D_{n}(\mathrm{~m})$ & various & various & 0.067 & Normal \\
$\Delta$ & 1.233 & 0.047 & 0.038 & Normal \\
$\cot \alpha$ & 1.5 & 0.075 & 0.05 & Normal \\
$H_{s}(\mathrm{~m})$ & Parameters of $A, B$, and & $k$ & Weibull \\
$F_{H_{s}}(\mathrm{~m})$ & - & 0.25 & - & Normal \\
$a_{1}$ & 1.0 & 0.10 & 0.10 & Normal \\
\hline
\end{tabular}


Table 4. Statistical characteristics of design variables for van der Meer (1988c) formula.

\begin{tabular}{|c|c|c|c|c|}
\hline Variable & Mean & $\begin{array}{l}\text { Standard } \\
\text { deviation }\end{array}$ & $\begin{array}{c}\text { Coefficient of } \\
\text { variation }\end{array}$ & Distribution \\
\hline$D_{n} \quad(\mathrm{~m})$ & various & various & 0.067 & Normal \\
\hline$\Delta$ & 1.233 & 0.047 & 0.038 & Normal \\
\hline$N_{0}$ & 1.5 & 0.375 & 0.25 & Normal \\
\hline$H_{s}(\mathrm{~m})$ & \multicolumn{3}{|c|}{ Parameters of $A, B$, and $k$} & Weibull \\
\hline$F_{H_{s}}(\mathrm{~m})$ & - & 0.25 & - & Normal \\
\hline$s_{Z}$ & various & various & 0.059 & Normal \\
\hline$a_{2}$ & 1.0 & 0.10 & 0.10 & Normal \\
\hline
\end{tabular}


Table 5. Probabilities of failure (\%) of armor blocks calculated by various reliability design methods for different sections.

\begin{tabular}{lccc}
\hline Method & $\begin{array}{c}\text { Section 7 } \\
\text { (Before reinforcement) }\end{array}$ & $\begin{array}{c}\text { Section 7 } \\
\text { (After reinforcement) }\end{array}$ & $\begin{array}{c}\text { Section 11 } \\
\text { (After reinforcement) }\end{array}$ \\
\hline Level 1 & 60 & 18 & 18 \\
Level 2 & 60 & 23 & 25 \\
Level 3 & 40 & 3 & 20 \\
\hline
\end{tabular}


Table 6. Partial safety factors for sliding of caissons (Burcharth and Sørensen 2000).

\begin{tabular}{ccc}
\hline$P_{f}$ & $\gamma_{H_{s}}$ & $\gamma_{Z}$ \\
\hline 0.01 & 1.3 & 1.6 \\
0.05 & 1.2 & 1.5 \\
0.10 & 1.2 & 1.3 \\
0.20 & 1.1 & 1.2 \\
0.40 & 1.0 & 1.1 \\
\hline
\end{tabular}


Table 7. Statistical characteristics of design variables for sliding of caisson.

\begin{tabular}{ccccc}
\hline Variable & Mean & $\begin{array}{c}\text { Standard } \\
\text { deviation }\end{array}$ & $\begin{array}{c}\text { Coefficient of } \\
\text { variation }\end{array}$ & Distribution \\
\hline$\mu$ & 1.05 & 0.16 & 0.15 & Normal \\
$W_{w}$ & 1.01 & 0.05 & 0.05 & Normal \\
$P$ & 0.72 & 0.13 & 0.18 & Normal \\
$U$ & 0.72 & 0.13 & 0.18 & Normal \\
\hline
\end{tabular}


Table 8. Probabilities of failure (\%) of caisson sliding calculated by various reliability design methods for Section 11.

\begin{tabular}{ccc}
\hline Method & Before reinforcement & After reinforcement \\
\hline Level 1 & 45 & 20 \\
Level 2 & 95 & 20 \\
Level 3 & 80 & 18 \\
\hline
\end{tabular}




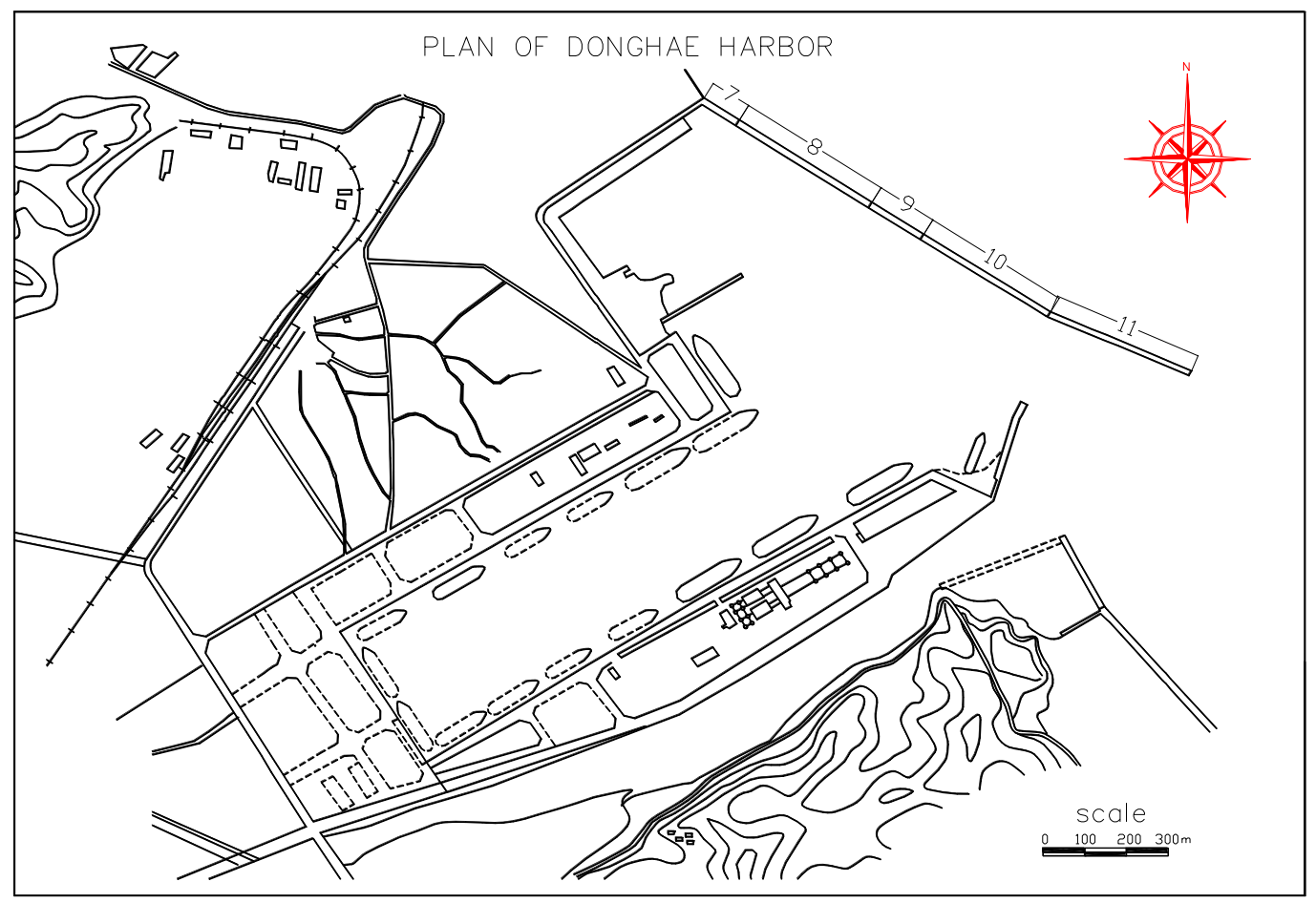

Figure 1. Layout of Donghae Harbor. 


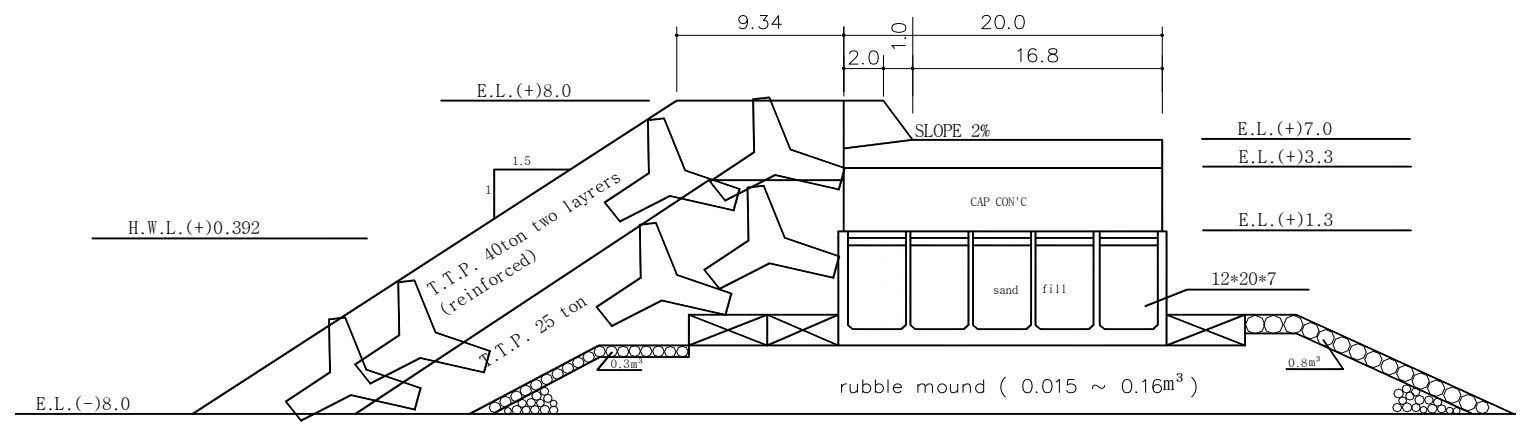

Figure 2. Cross-section of Section 7 after reinforcement (unit: m). 


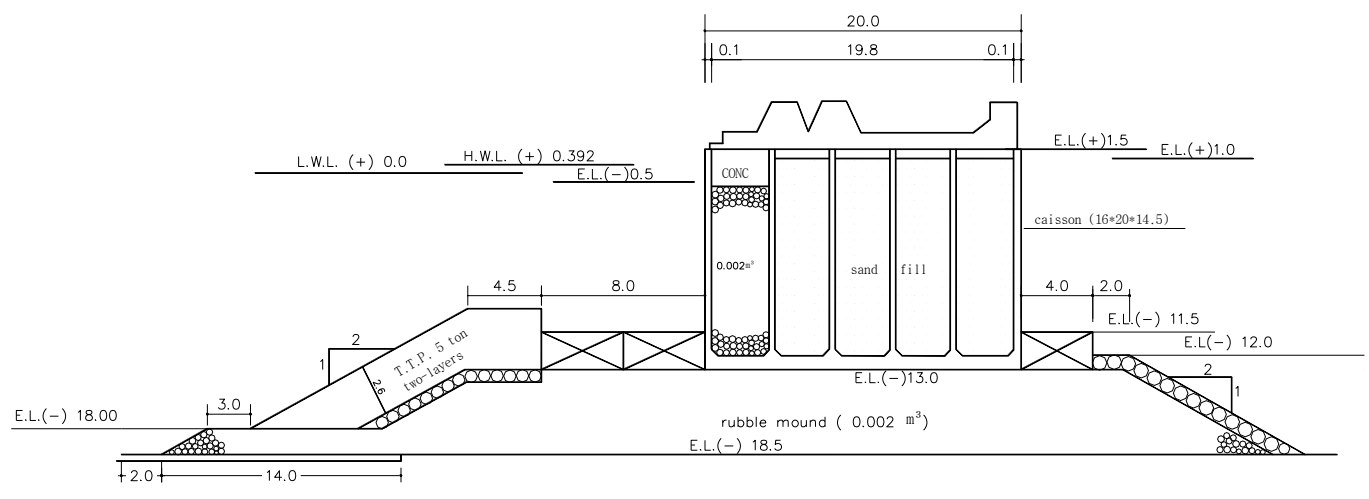

Figure 3. Cross-section of Section 11 before reinforcement (unit: m). 


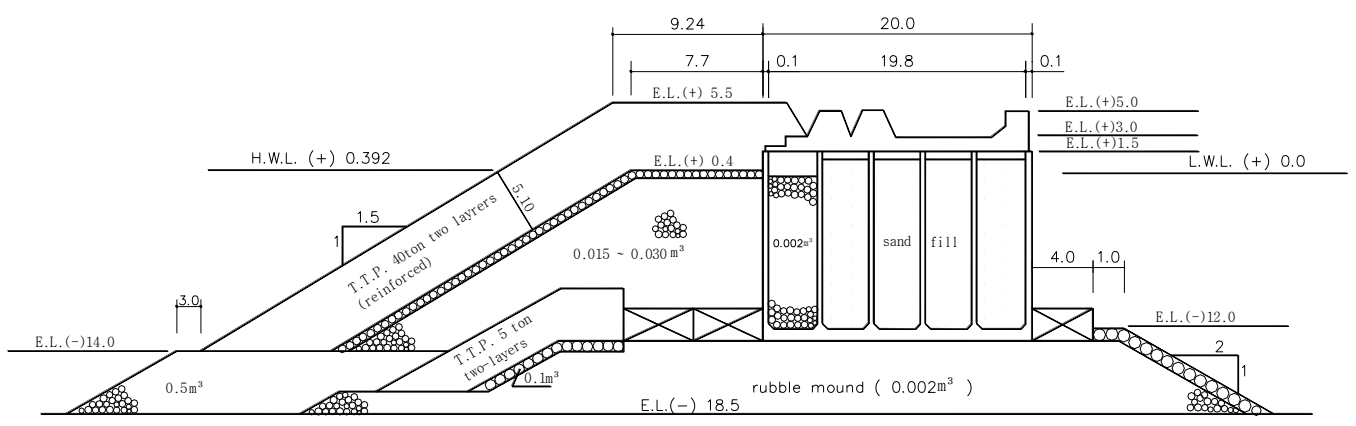

Figure 4. Cross-section of Section 11 after reinforcement (unit: m). 


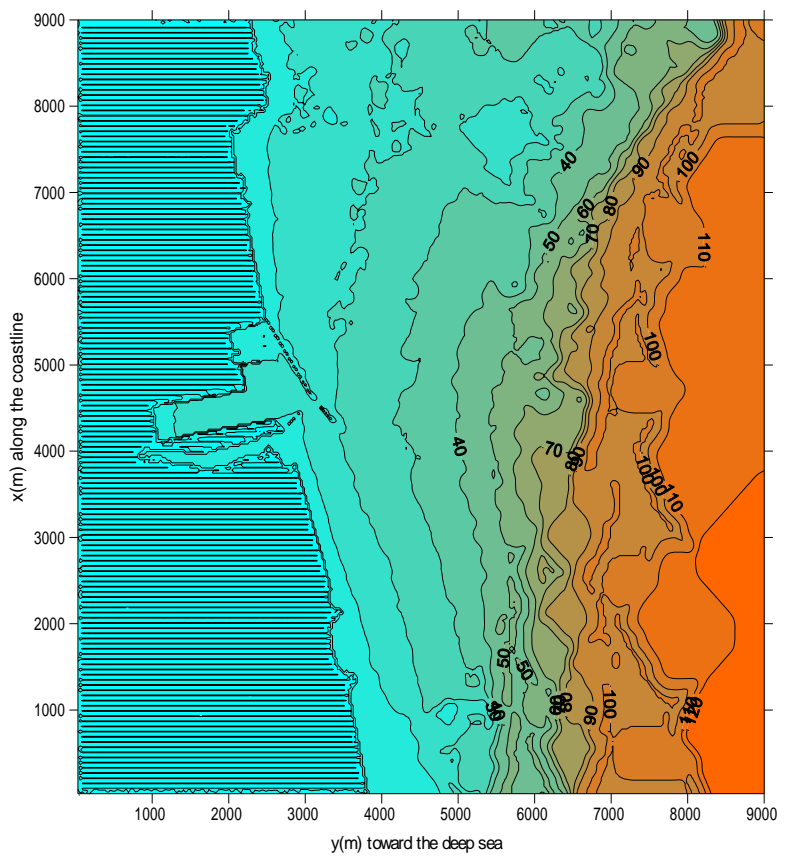

Figure 5. Bathymetry of numerical wave transformation model domain. 


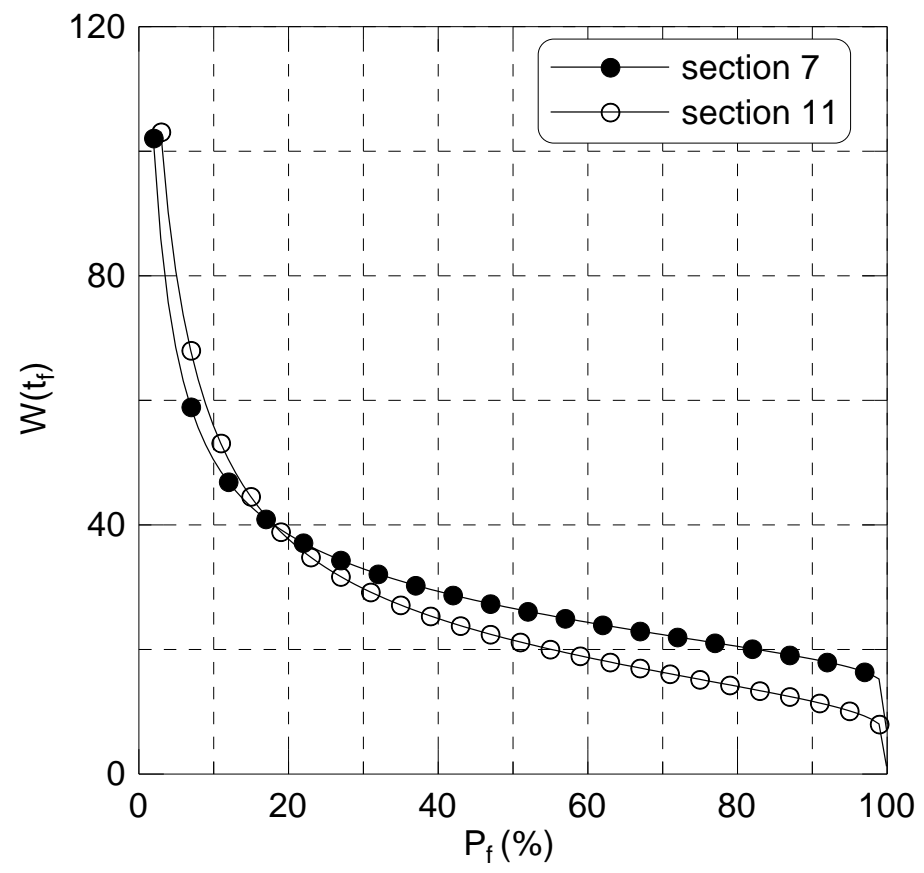

Figure 6. Weight of Tetrapod versus probability of failure calculated by Level 1 method. 


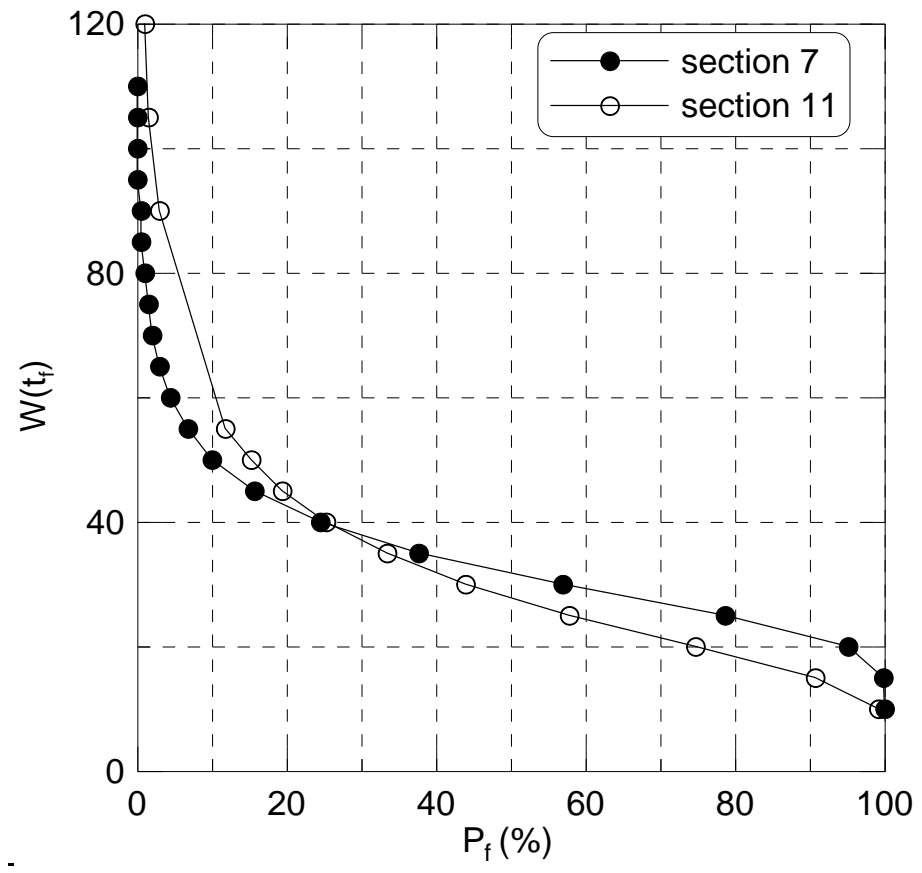

Figure 7. Weight of Tetrapod versus probability of failure calculated by Level 2 method. 


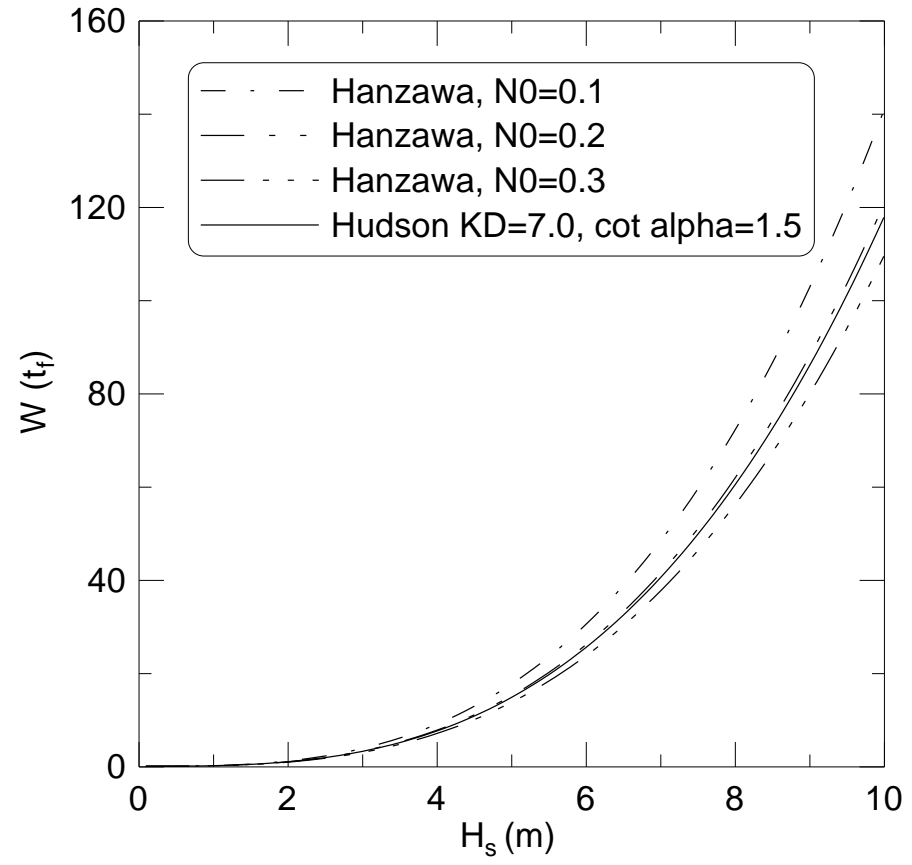

Figure 8. Relationship between significant wave height and weight of Tetrapod calculated by Hudson(1959) and Hanzawa et al.(1996) formulas. 


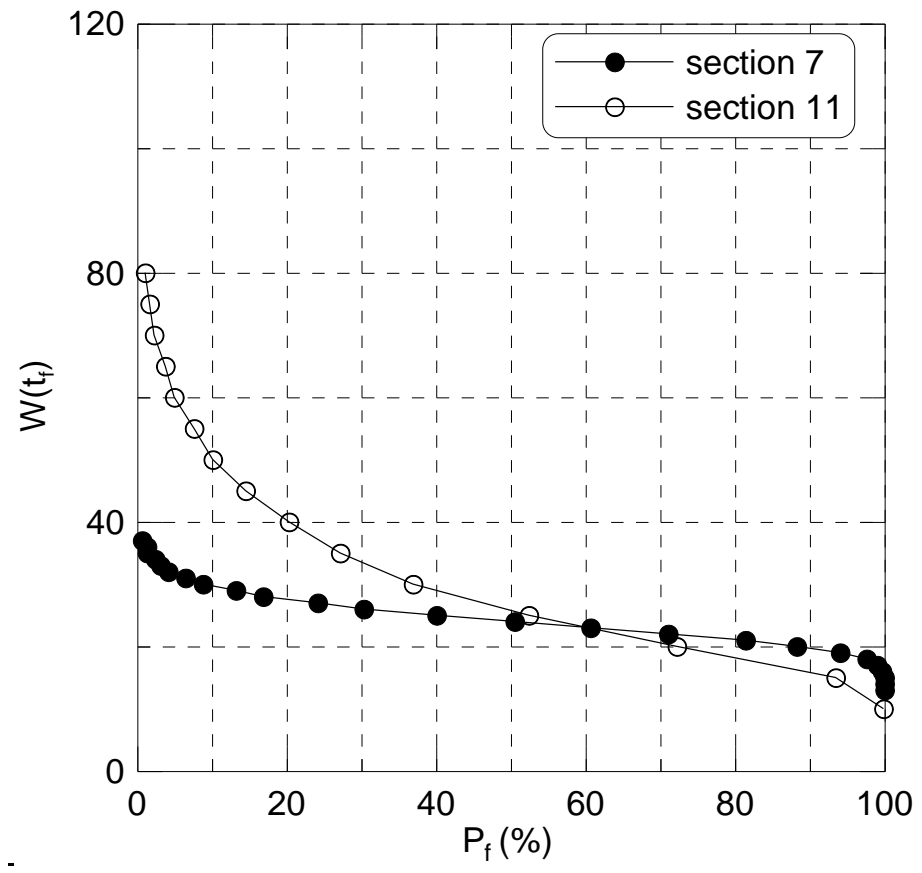

Figure 9. Weight of Tetrapod versus probability of failure calculated by Level 3 method. 


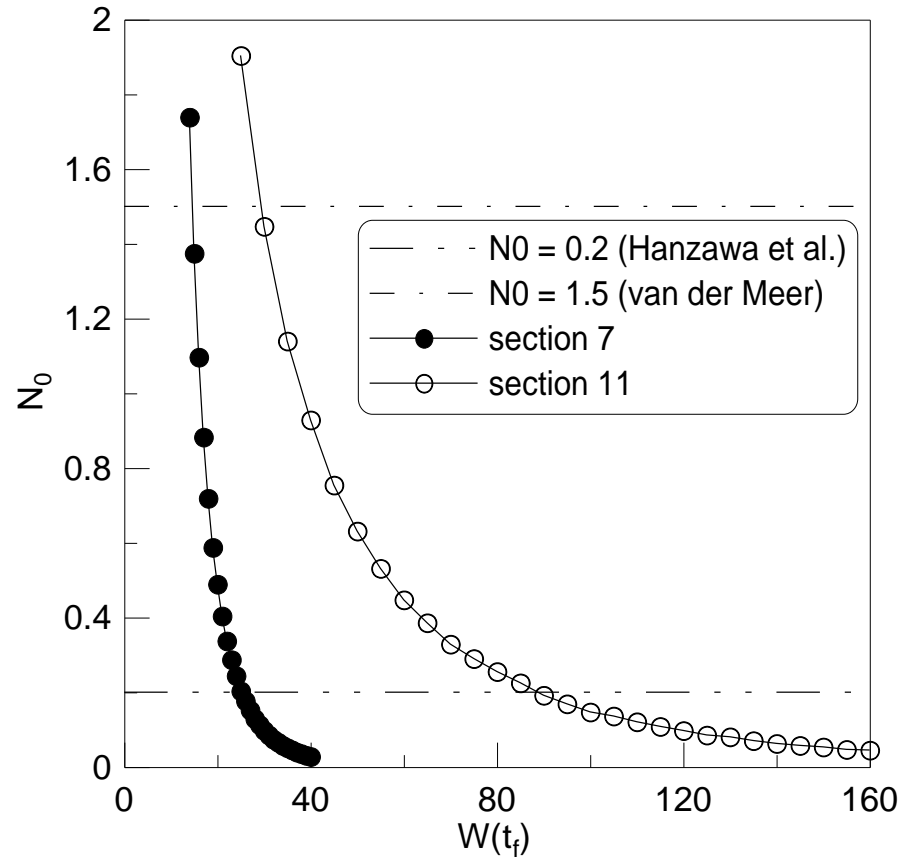

Figure 10. Relative damage versus weight of Tetrapod calculated by Level 3 method. 


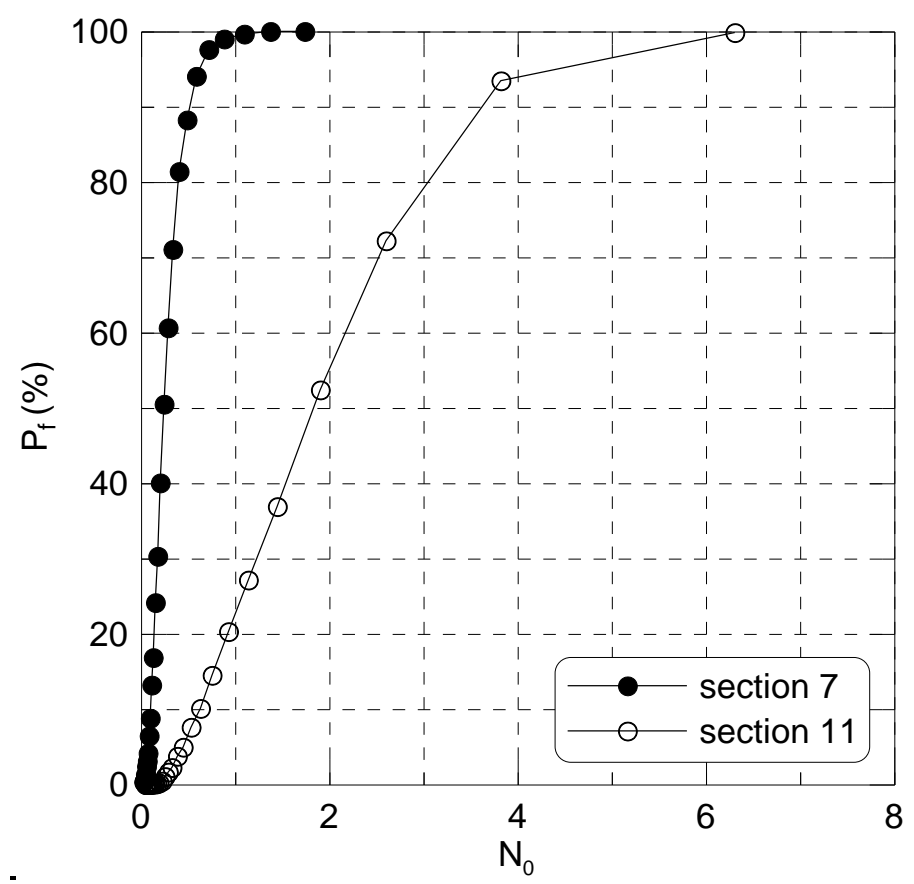

Figure 11. Probability of failure versus relative damage calculated by Level 3 method. 


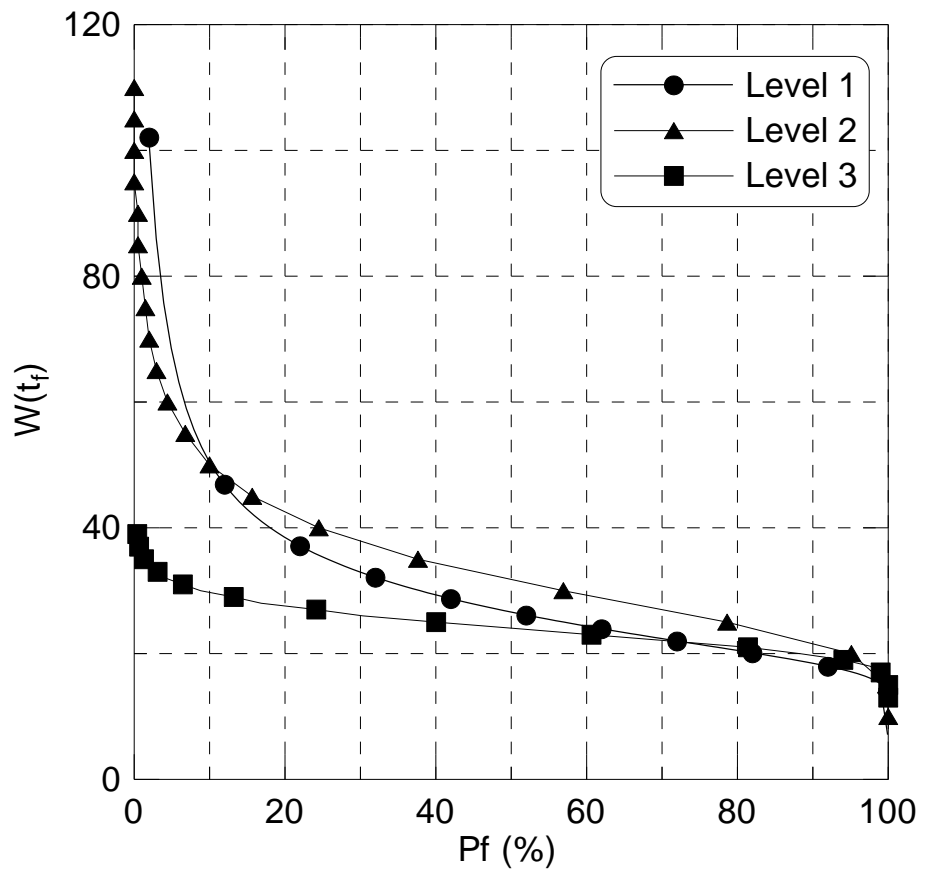

Figure 12. Weight of Tetrapod versus probability of failure calculated by various reliability design methods for Section 7. 


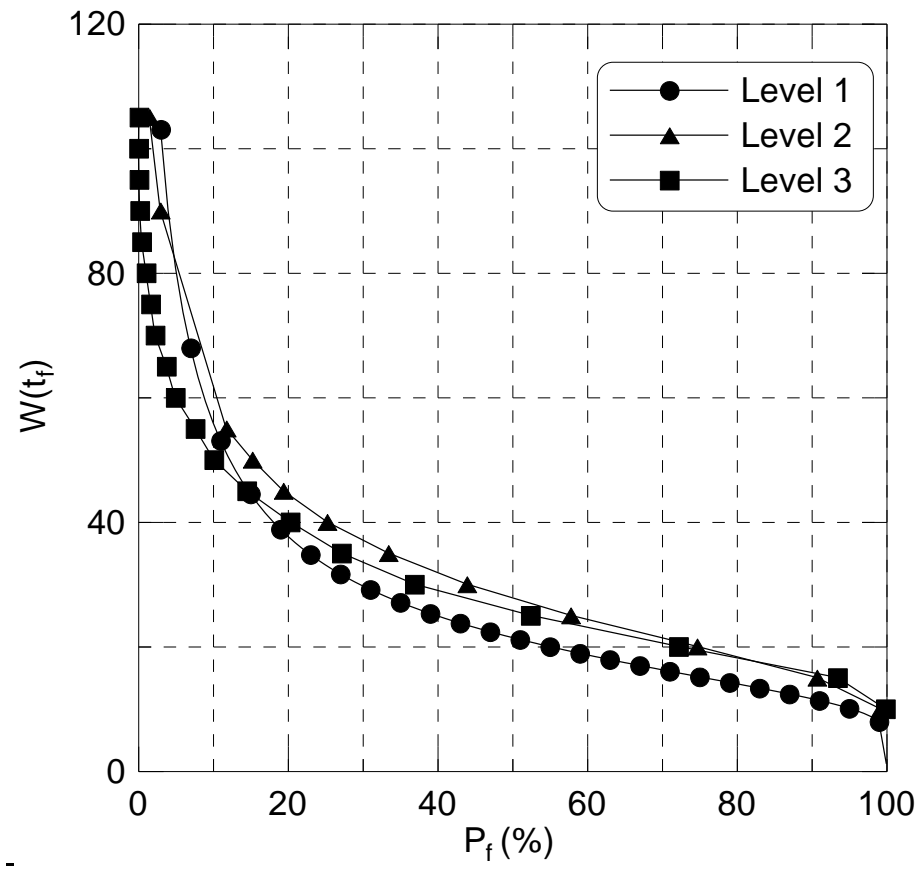

Figure 13. Weight of Tetrapod versus probability of failure calculated by various reliability design methods for Section 11. 


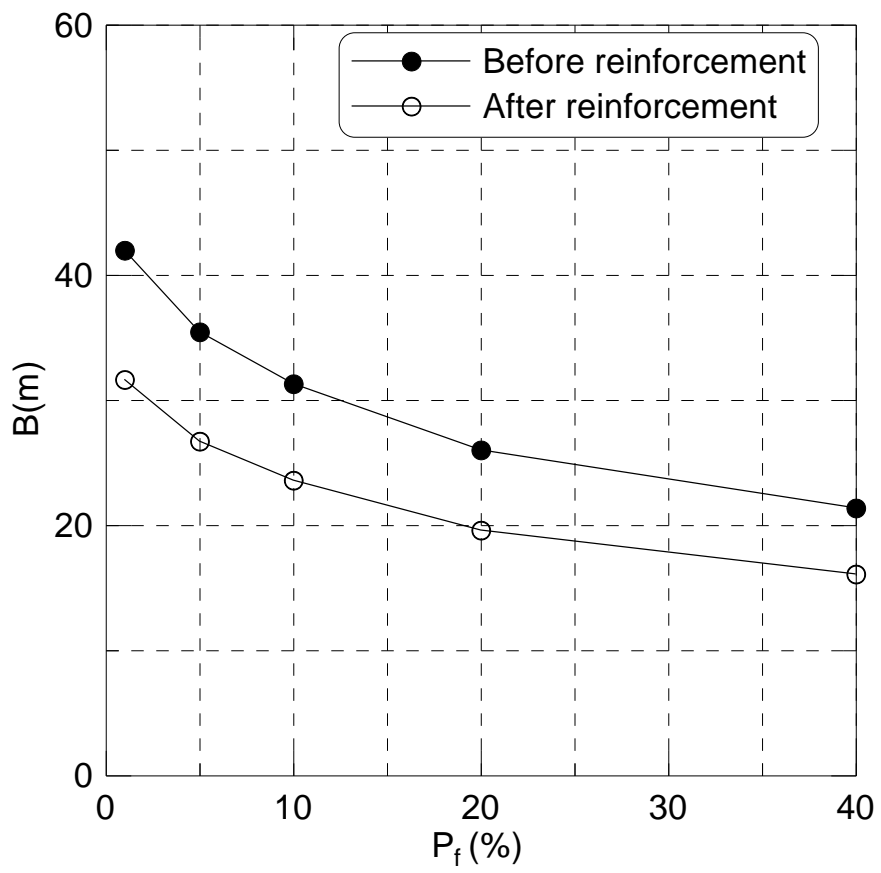

Figure 14. Width of caisson versus probability of failure calculated by Level 1 method. 


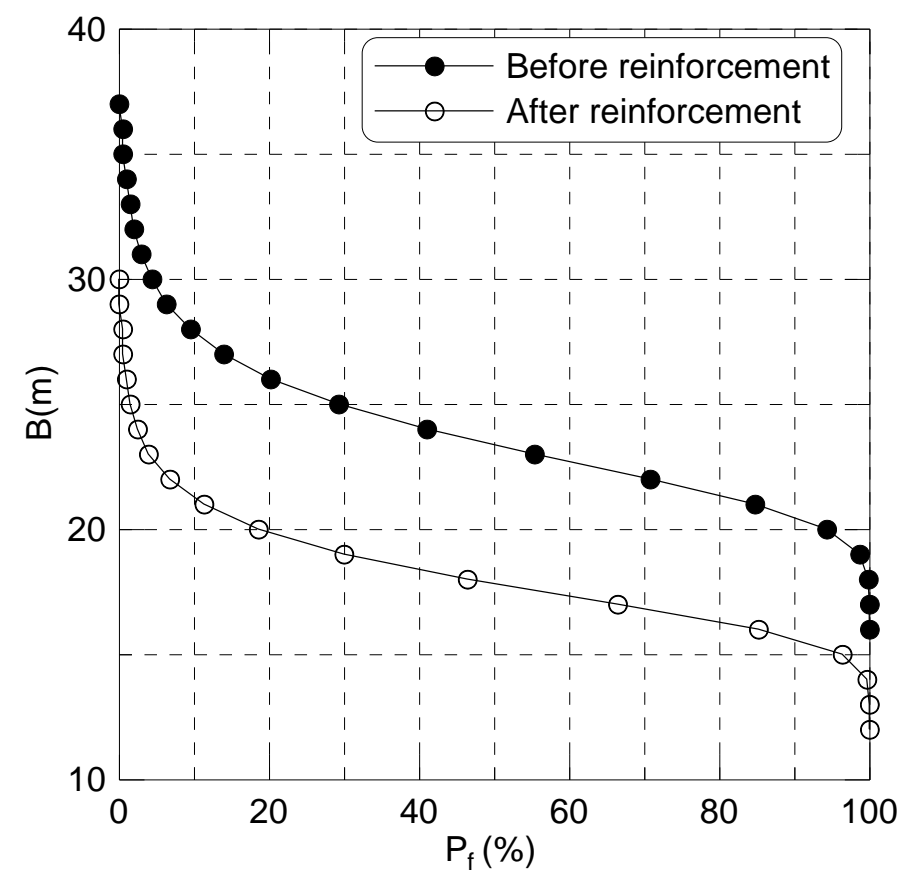

Figure 15. Width of caisson versus probability of failure calculated by Level 2 method. 


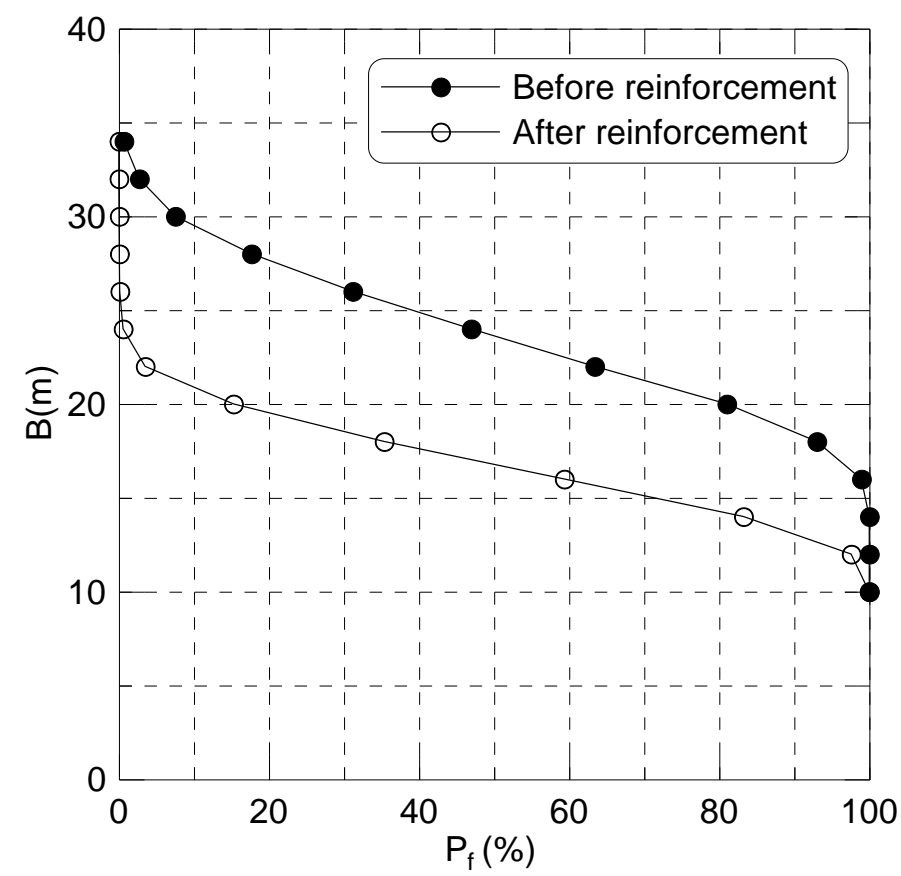

Figure 16. Width of caisson versus probability of failure calculated by Level 3 method. 


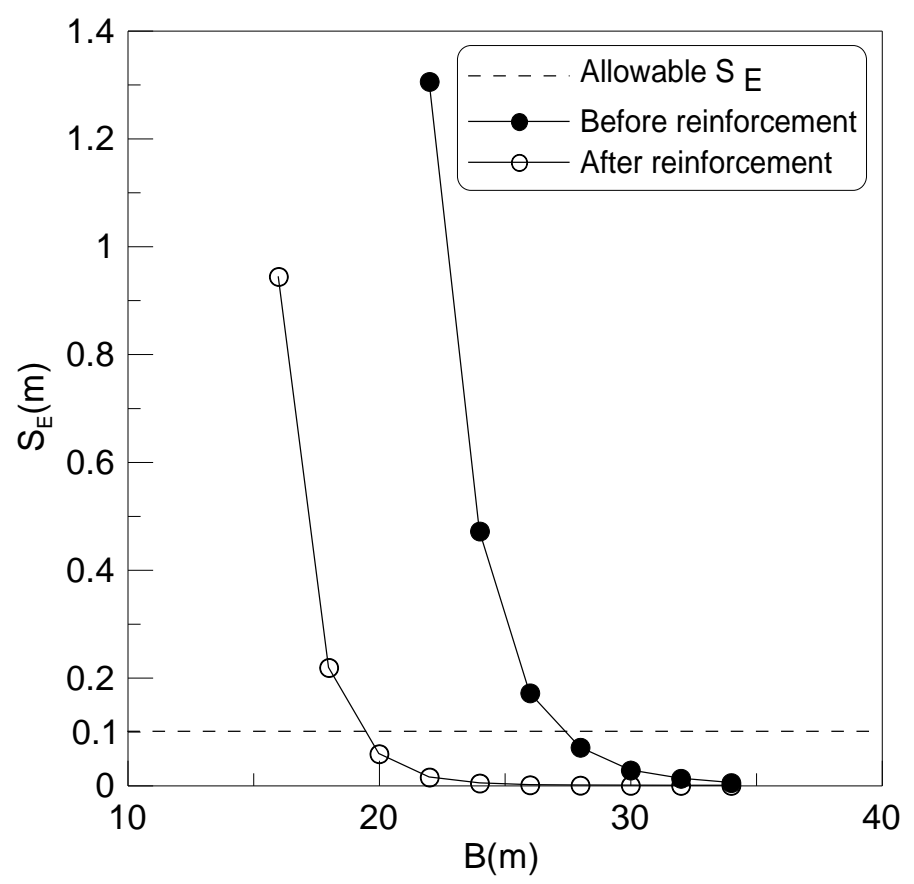

Figure 17. Expected sliding distance versus width of caisson calculated by Level 3 method. 


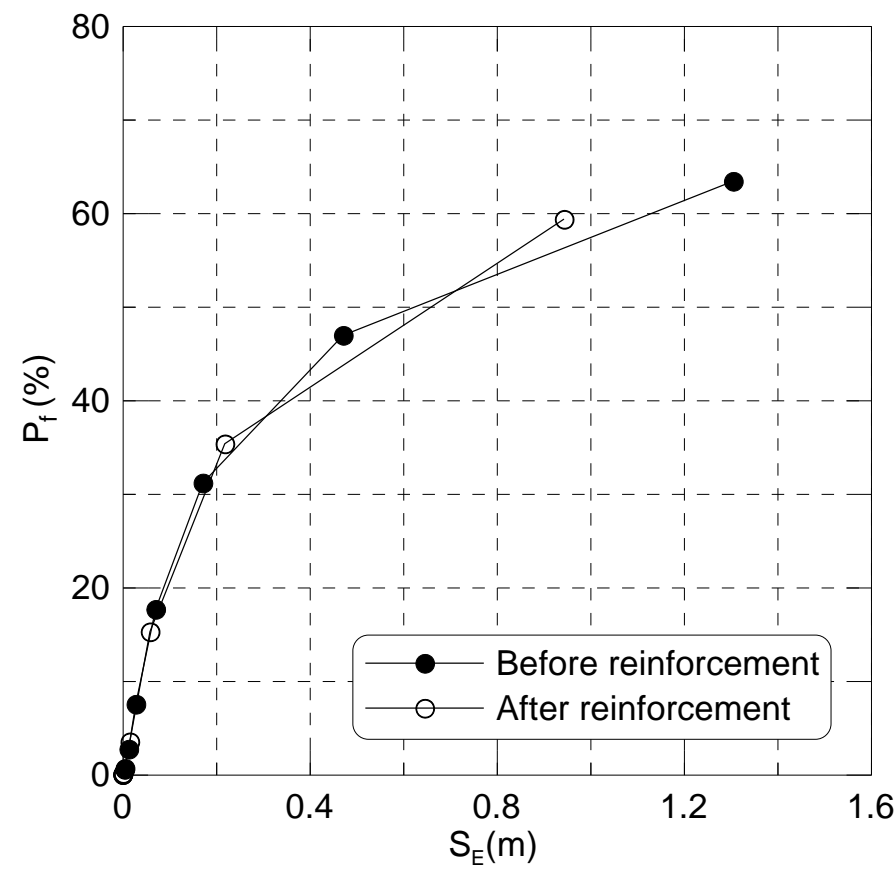

Figure 18. Probability of failure versus expected sliding distance calculated by Level 3 method. 


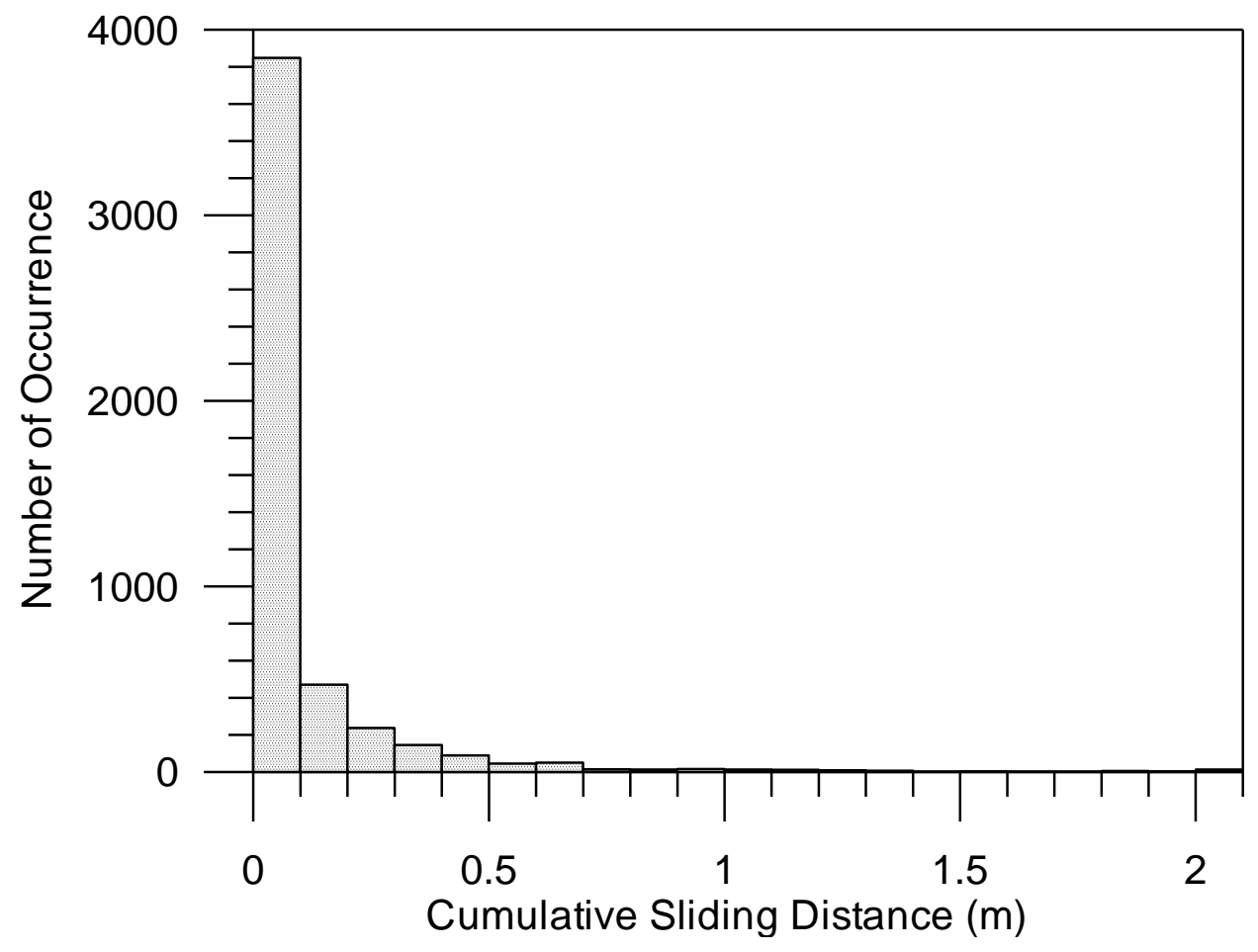

Figure 19. Number of occurrence of cumulative sliding distance for caisson of width of $19.1 \mathrm{~m}$ after reinforcement. 


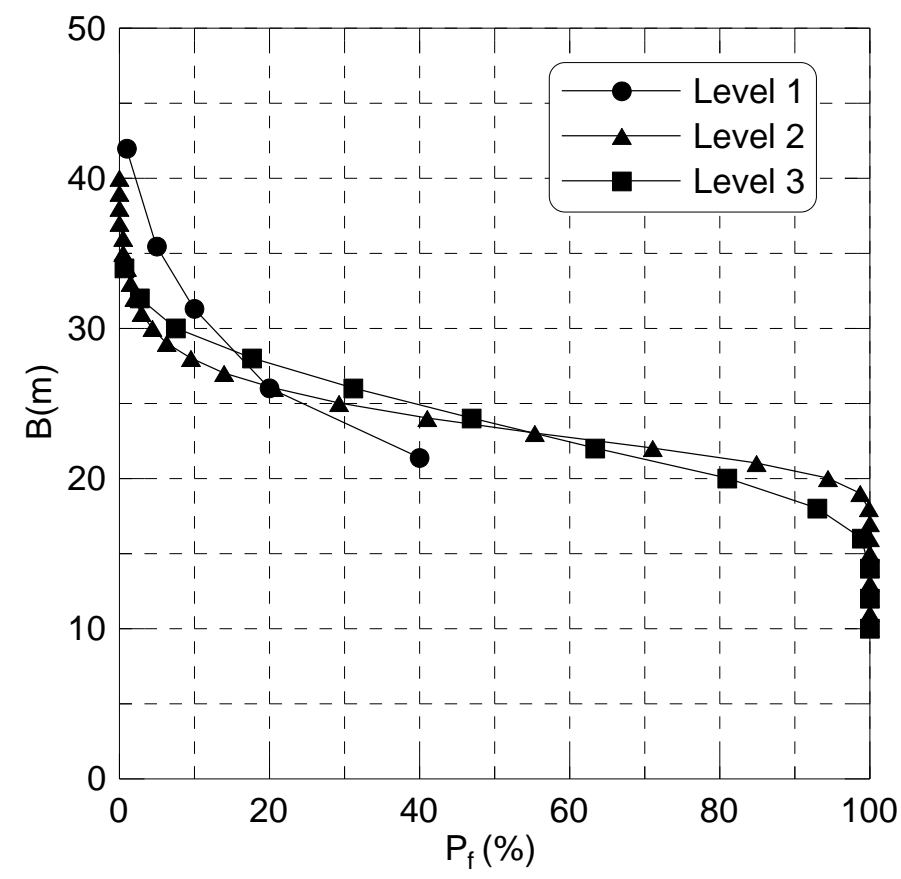

Figure 20. Width of caisson versus probability of failure calculated by various reliability design methods for Section 11 before reinforcement. 


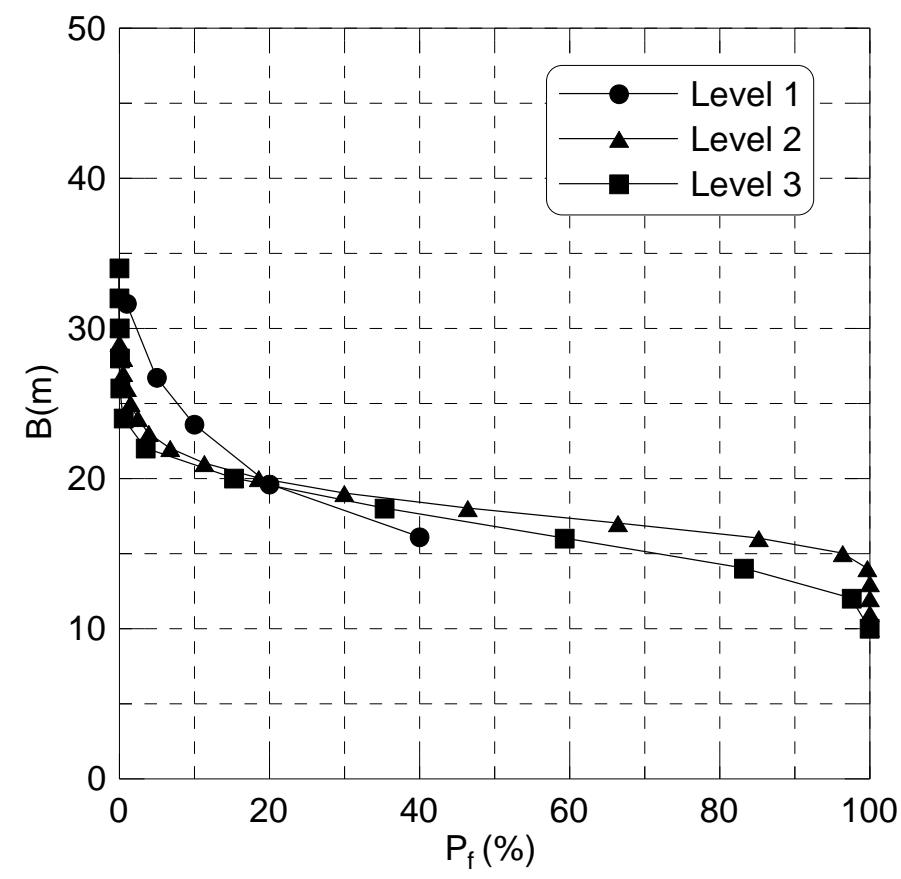

Figure 21. Width of caisson versus probability of failure calculated by various reliability design methods for Section 11 after reinforcement. 